Article

\title{
Application of Novel C-TiO 2 -CFA/PAN Photocatalytic Membranes in the Removal of Textile Dyes in Wastewater
}

\author{
Amkelwa Mpelane ${ }^{1}$, David M. Katwire ${ }^{1}$, Henry H. Mungondori ${ }^{1,2, *} \mathbb{C}$, Pardon Nyamukamba ${ }^{1}$ \\ and Raymond T. Taziwa ${ }^{2}$ (i) \\ 1 Chemistry Department, University of Fort Hare, 1 King Williams Town Road, Alice 5700, South Africa; \\ mpelaneamkelwa@gmail.com (A.M.); dkatwire@ufh.ac.za (D.M.K.); pnyamukamba@ufh.ac.za (P.N.) \\ 2 Department of Applied Chemistry, Walter Sisulu University, Old King Williams Town Road, Fort Jackson, \\ East London 5200, South Africa; rtaziwa@wsu.ac.za \\ * Correspondence: hmungondori@wsu.ac.za; Tel.: +27-605-038-175
}

Received: 6 April 2020; Accepted: 29 April 2020; Published: 9 August 2020

check for updates

\begin{abstract}
The existence of dye effluent in environmental water bodies is becoming a growing concern to environmentalists and civilians due to negative health effects. In this study, a novel poly(acrylonitrile)-membrane-supported carbon-doped titanium dioxide-coal fly ash nanocomposite $\left(\mathrm{C}-\mathrm{TiO}_{2}-\mathrm{CFA} / \mathrm{PAN}\right)$ was prepared and evaluated in the removal of textiles dyes (methyl orange and golden yellow) in water. The $\mathrm{C}-\mathrm{TiO}_{2}$-CFA nanocomposite was prepared via sol-gel synthesis and immobilized on PAN membrane prepared via phase inversion technique. The photocatalyst was characterized by FTIR, XRD, BET surface area analysis, SEM, EDX, and DRS. FTIR analysis confirmed the existence of the expected functional groups, and XRD revealed that the $\mathrm{C}-\mathrm{TiO}_{2}$ was predominantly in the anatase phase, which exhibited the highest photocatalytic activity. The optimum $\mathrm{C}-\mathrm{TiO}_{2}-\mathrm{CFA}$ photocatalyst load on the PAN membrane was $2 \% \mathrm{w} / \mathrm{w}$, and it achieved degradation efficiencies of $99.86 \%$ and $99.20 \%$ for MO and GY dyes, respectively, at $\mathrm{pH} 3.5$, using a dye concentration of $10 \mathrm{ppm}$,

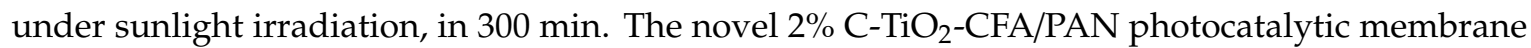
proved to be very effective in the removal of textile dyes' water. Three reusability cycles were carried out, and no significant changes were observed in the photocatalytic efficiencies. Immobilization on PAN membrane allowed easy recovery and reuse of the photocatalyst.
\end{abstract}

Keywords: carbon-doped titanium dioxide; coal fly ash; photocatalysis; poly(acrylonitrile); methyl orange; golden yellow; water treatment

\section{Introduction}

Population growth globally has led to a boom in industrial production. This growth in pollution-intensive industries, such as the textile industry, is one of the major contributors to the global water crisis [1-4]. Other factors contributing to water shortage include recurrent elevated temperatures and growing irrigation-water demands [5]. The textile dyeing industry is one of the biggest water consumers and polluters, after the agricultural industry [2,4]. Textile effluent holds various inorganic and organic compounds, some of which greatly contribute to the pollution of available fresh water sources if left untreated $[3,4,6]$. Most of the substances contained in textile wastewater are toxic and non-biodegradable. Basiglini and co-workers, in 2018, reported the presence of aromatic amines, which are degradation by-products in treated water [7]. Such toxic elements in water and wastewater pose risks to human health and serious harm to ecosystems [4]. Dyes like rhodamine B have been observed to cause skin damage, respiratory tract irritation, and, in some cases, liver damage [8]. The existence of emerging recalcitrant pollutants in water has prompted researchers 
to work on improving existing water treatment methods, as well as develop new cost-effective and efficient techniques that can remove such pollutants. This is pivotal in safeguarding human health and preserving natural ecosystems.

Advanced oxidation processes, such as semiconductor photocatalysis, are among some of the most promising water treatment methods that can remove several pollutants from water [8]. However, to effectively treat water, a combination of suitable techniques is required. Titanium dioxide $\left(\mathrm{TiO}_{2}\right)$ has received great researcher attention as a promising photocatalyst for water treatment. It is the semiconductor of choice, owing to attributes such as chemical stability, relative non-toxicity, enhanced photostability, and strong oxidation ability [8-10]. Despite its superior performance in water treatment, $\mathrm{TiO}_{2}$ has the following major drawbacks: a large bandgap, which restricts it to the UV-light section of the solar spectrum (UV light only accounts for $5 \%$ of the solar spectrum); high recombination rates of electron hole pairs; and the small size of the nanoparticles, which makes recovery difficult after water treatment [9-11]. To improve the spectral response of $\mathrm{TiO}_{2}$, as well as to address the short electron-hole recombination problem, researchers have used approaches such as metal and non-metal doping, plasmon enhancement, and combination with inorganic particles, as well as other semiconductors [11-15]. The literature has also reported the use of polymers, clay, and activated carbon as support materials for titanium dioxide photocatalyst, to avoid the problems associated with post-recovery of the fine nanoparticles [16-18]. Such modifications allow for the fabrication of $\mathrm{TiO}_{2}$ with improved photocatalytic properties.

In this study, sol-gel synthesis was used to prepare a novel carbon-doped titanium dioxide-coal fly ash photocatalytic nanocomposite $\left(\mathrm{C}-\mathrm{TiO}_{2}-\mathrm{CFA}\right)$. It is well documented in the literature that carbon doping allows efficient light utilization, therefore enhancing photocatalytic activity of titanium dioxide. Carbon introduced into the lattice structure of $\mathrm{TiO}_{2}$ also acts as a trap for electrons, hence prolonging the lifespan of electron hole pairs [19-21]. It is also reported in the literature that clusters of $\mathrm{sp}^{2}$ carbon allow enhanced absorption of light, specifically in the visible range, which is a wide spectrum $(40 \%$ of the solar spectrum) $[8,22]$. The essence of this study was to create an efficient and cost-effective water treatment method, as well as find an alternative use for coal fly ash (CFA), an abundant by-product from coal combustion, as a way of environmental clean-up. Statistics show that only one-quarter of the annual CFA production finds an alternative use. In the past five years, the annual CFA production was estimated to be over 500 million tons $[23,24]$. CFA is known to cause air and water pollution, through the release of small particles that can be suspended in the air and the leaching of heavy metals, such as arsenic, into the water, depending on its composition. Prolonged exposure to CFA has also been observed to cause irritation of the respiratory tract, nose, skin, and eyes in human beings $[23,25]$. Hence, finding alternative uses for this solid waste material will rid the environment of its negative effects. The composition and properties of CFA makes it an ideal material for use in water treatment. The unburnt carbon found in CFA has very high adsorption properties, making it a good material for enhancing the adsorption properties of $\mathrm{TiO}_{2}$, to improve its photocatalytic properties [25]. To avoid the problem of post-recovery of fine nanocomposite particles, the prepared C- $\mathrm{TiO}_{2}$-CFA nanocomposite was immobilized on poly(acrylonitrile) (PAN) membranes, which were prepared via the phase-inversion technique. The attributes of PAN which make it suitable for making membranes are good chemical, mechanical and thermal properties, as well as resistance to solvents [26]. According to the available literature, this is the first time such a polymer-supported photocatalytic nanocomposite $\left(\mathrm{C}-\mathrm{TiO}_{2}-\mathrm{CFA} / \mathrm{PAN}\right)$ has been reported.

\section{Results}

\subsection{Chemical Structure}

The prepared $\mathrm{C}-\mathrm{TiO}_{2}-\mathrm{CFA}$ nanocomposite and the $\mathrm{C}-\mathrm{TiO}_{2}-\mathrm{CFA} / \mathrm{PAN}$ photocatalytic membranes were fully characterized, using FTIR, XRD, SEM-EDS, and DRS. 


\subsubsection{Fourier Transform Infrared Spectroscopy (FTIR) Analysis}

FTIR analysis was used to identify the functional groups present in the prepared photocatalytic nanocomposite and the photocatalytic nanocomposite membranes. The FTIR spectra of the starting materials are also included, for comparison purposes.

The broad peak occurring around $3400 \mathrm{~cm}^{-1}$ in all the spectra, except for that of CFA, is attributed to the stretching vibrations of the surface hydroxyl groups. The major peaks associated with Ti-O, Ti-O-Ti, and O-Ti-O stretching vibrations of titanium dioxide occur at 756 and $555 \mathrm{~cm}^{-1}$. The $\mathrm{O}-\mathrm{H}$ bending modes of adsorbed water occur at $1644 \mathrm{~cm}^{-1}$ in the spectra of $\mathrm{C}-\mathrm{TiO}_{2}, \mathrm{C}-\mathrm{TiO}_{2}-\mathrm{CFA}$, and $\mathrm{C}-\mathrm{TiO}_{2}-\mathrm{CFA} / \mathrm{PAN}$. The peak located around $1095 \mathrm{~cm}^{-1}$ is associated with C-O-C bonds (Figure $1 \mathrm{~b}-\mathrm{d}$ ). The spectrum for CFA has major peaks located at 1047 and $566 \mathrm{~cm}^{-1}$, which can be ascribed to $\mathrm{Si}-\mathrm{O}-\mathrm{Si} / \mathrm{Al}-\mathrm{O}-\mathrm{Al}$ anti-symmetric stretching vibrations and Si-O-Si. The peak at $1047 \mathrm{~cm}-1 \mathrm{can}$ also be seen in the spectra of $\mathrm{C}-\mathrm{TiO}_{2}-\mathrm{CFA}$ and $\mathrm{C}-\mathrm{TiO}_{2}-\mathrm{CFA} / \mathrm{PAN}$ (Figure 1b,d). In the FTIR spectra for $\mathrm{PAN}$ and $\mathrm{C}-\mathrm{TiO}_{2}-\mathrm{CFA} / \mathrm{PAN}$ membranes (Figure $1 \mathrm{a}, \mathrm{b}$ ), the peaks located at 2915 and $1472 \mathrm{~cm}^{-1}$ can be attributed to the stretching and bending modes of C-H. The small peak at $2230 \mathrm{~cm}^{-1}$ can be ascribed to the stretching vibrations of the $C \equiv N$ group. The peak at $1657 \mathrm{~cm}^{-1}$ can be attributed to the $C=C$ stretching vibrations of the vinyl acetate co-monomer used in the synthesis of PAN. The existence of the expected functional groups in the $\mathrm{C}-\mathrm{TiO}_{2}-\mathrm{CFA} / \mathrm{PAN}$ photocatalytic membranes points toward a successful preparation process.

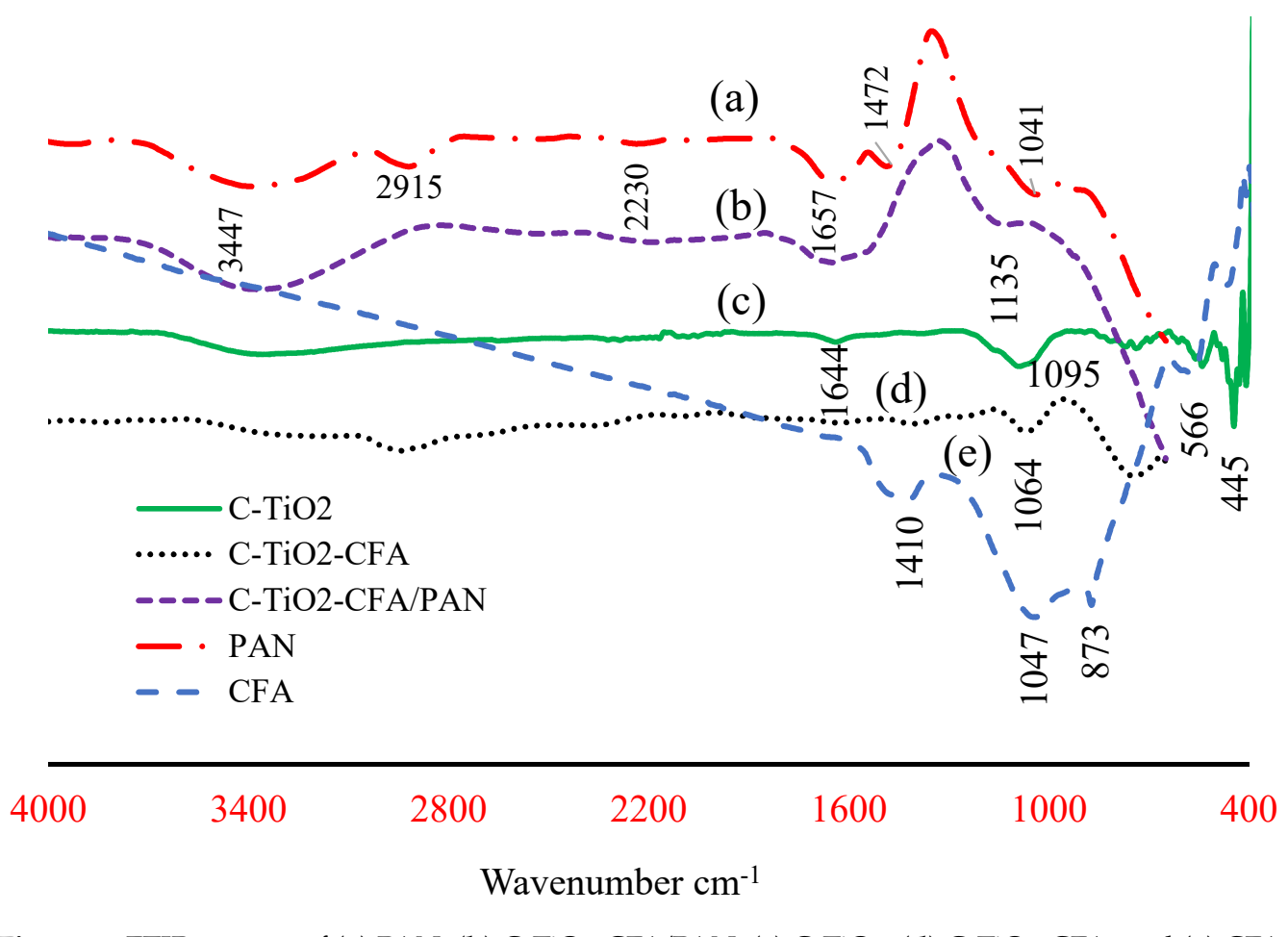

Figure 1. FTIR spectra of (a) PAN, (b) C-TiO $2-\mathrm{CFA} / \mathrm{PAN}$, (c) $\mathrm{C}-\mathrm{TiO}_{2}$, (d) $\mathrm{C}-\mathrm{TiO}_{2}-\mathrm{CFA}$, and (e) CFA.

\subsubsection{X-Ray Diffraction (XRD) and BET (Brunauer-Emmett-Teller) Surface Area Analyses}

The crystallinity and phase composition of the prepared $\mathrm{C}-\mathrm{TiO}_{2}-\mathrm{CFA}$ nanocomposite were probed with XRD analysis (Figure 2). The spectrum obtained was compared to those of $\mathrm{C}-\mathrm{TiO}_{2}$ and CFA. 


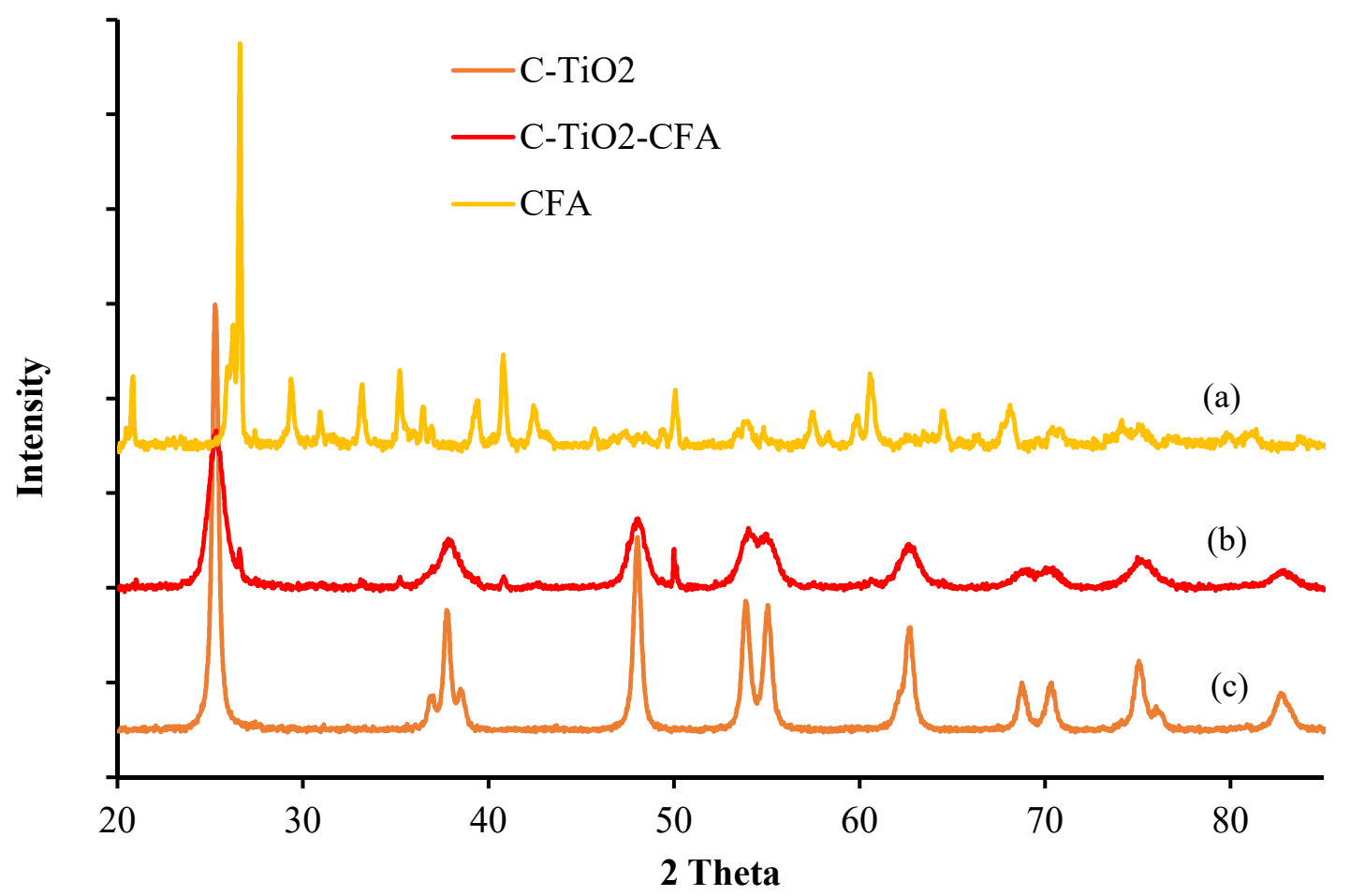

Figure 2. XRD patterns of (a) $\mathrm{CFA}$, (b) $\mathrm{C}-\mathrm{TiO}_{2}-\mathrm{CFA} / \mathrm{PAN}$, and (c) $\mathrm{C}-\mathrm{TiO}_{2}$.

In the XRD pattern for $\mathrm{C}-\mathrm{TiO}_{2}$, the following peaks were identified: $25.4^{\circ}, 37.8^{\circ}, 48.5^{\circ}, 53.7^{\circ}, 55^{\circ}$, $62.8^{\circ}, 68.9^{\circ}, 70.3^{\circ}, 75.2^{\circ}$, and $83.2^{\circ}$. These peaks can be attributed to the anatase phase of titanium dioxide (Figure 1c). In the CFA diffraction pattern, the diffraction peaks at $2 \theta$ values of $20.8^{\circ}, 26.6^{\circ}$, $36.5^{\circ}, 50^{\circ}, 60^{\circ}$, and $79^{\circ}$ indicate the presence of quartz, while the peak at $20.8^{\circ}$ indicates the presence of berlinite. Diffraction peaks at $2 \theta$ values of $25.9^{\circ}, 26.2^{\circ}, 30.9^{\circ}, 33^{\circ}, 35^{\circ}, 40.8^{\circ}$, and $60.9^{\circ}$ indicate the presence of mullite in the CFA. The peak at $29^{\circ}$ can be ascribed to the presence of dolomite, and that at $29.4^{\circ}$ indicates the presence of calcite in the CFA. The diffraction pattern of $\mathrm{C}-\mathrm{TiO}_{2}-\mathrm{CFA}$ shows peaks that are not as sharp as those of $\mathrm{C}-\mathrm{TiO}_{2}$, owing to the introduction of CFA. The XRD spectrum for $\mathrm{C}-\mathrm{TiO}_{2}$-CFA shows at 2 theta angles of $20^{\circ}, 31^{\circ}, 33^{\circ}, 39^{\circ}$, and $48^{\circ}$, indicating the presence of CFA and those at $25^{\circ}, 37^{\circ}, 48^{\circ}, 55^{\circ}$, and $62^{\circ}$, which are attributed to the anatase phase of titanium dioxide. The presence of peaks for both $\mathrm{TiO}_{2}$ and CFA indicate the successful preparation of the photocatalytic nanocomposite. The Scherrer equation was used to calculate the particle size of the nanocomposite. Particles sizes of 11.62 and $13.98 \mathrm{~nm}$ were obtained for $\mathrm{C}-\mathrm{TiO}_{2}-\mathrm{CFA}$ and $\mathrm{C}-\mathrm{TiO}_{2}$, respectively. The particle sizes indicate that the nanocomposite was synthesized successfully in the nanometer range. These particles sizes correspond to BET surface areas of 114.02 and $93.2 \mathrm{~m}^{2} / \mathrm{g}$, respectively. Small particles sizes entail a very large surface for reactions to take place.

\subsubsection{Scanning Electron Microscopy (SEM) Analysis}

Scanning electron microscopy analysis was performed to study the morphology and size of the prepared nanocomposites and the photocatalytic membranes. The captured SEM images are shown in Figure 3. 

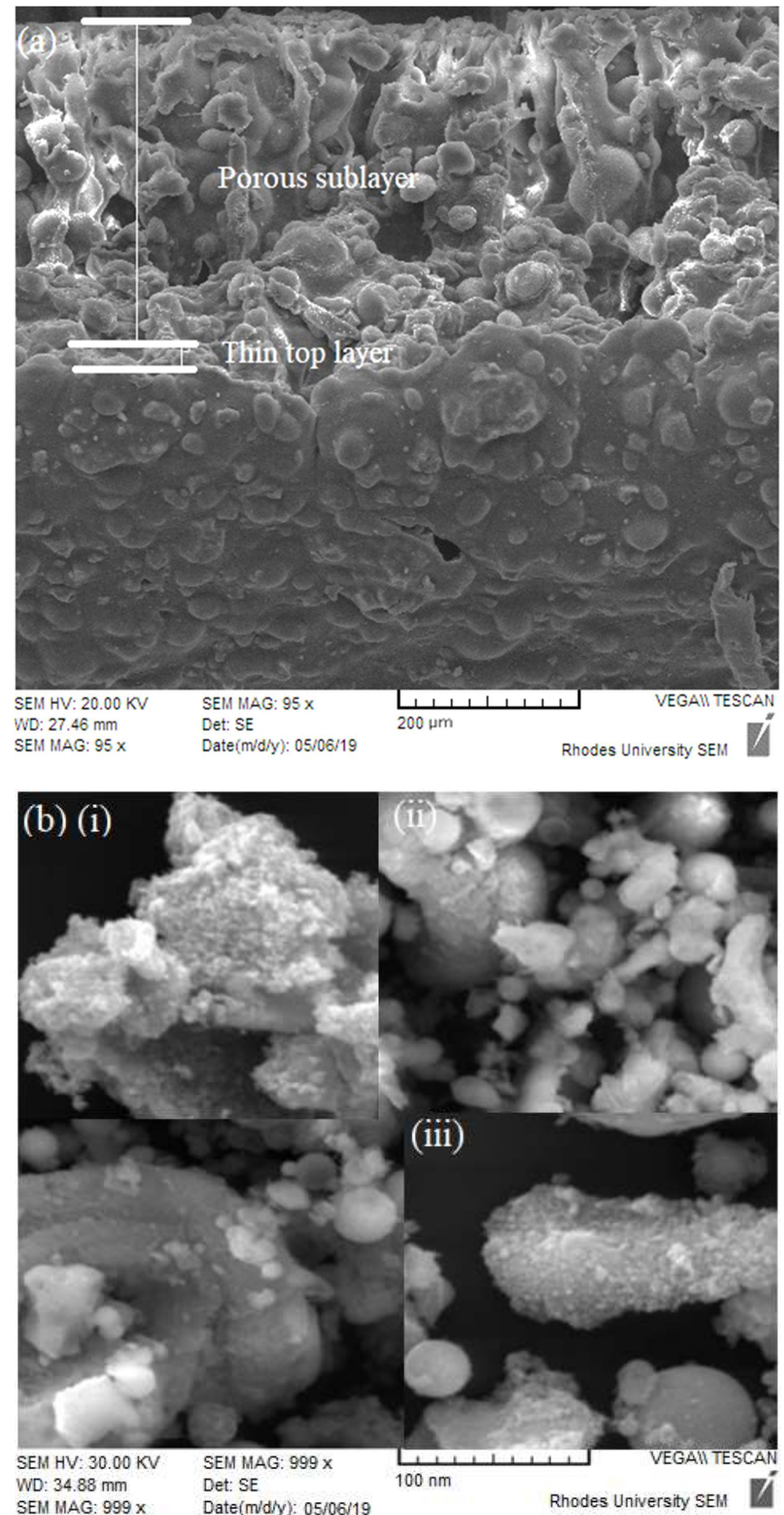

Figure 3. $\mathrm{SEM}$ images of (a) $\mathrm{C}-\mathrm{TiO}_{2}-\mathrm{CFA} / \mathrm{PAN}$ membrane and (b) (i) $\mathrm{C}-\mathrm{TiO}_{2}$, (ii) $\mathrm{CFA}$, (iii), and $\mathrm{C}-\mathrm{TiO}_{2}-\mathrm{CFA}$.

The image of the prepared photocatalytic membrane (Figure 3a) clearly shows the surface and cross-section of the membrane. The membrane has a thin top layer and a porous sublayer, which is typical of an asymmetric membrane. The membrane has a rough skin, owing to the $\mathrm{C}-\mathrm{TiO}_{2}-\mathrm{CFA}$ nanocomposite embedded within its matrix. The image of CFA (Figure 3b(ii)) shows ovoid-shaped particles, and these can also be seen in the image of the $\mathrm{C}-\mathrm{TiO}_{2}-\mathrm{CFA}$ nanocomposite (Figure $3 \mathrm{~b}$ (iii)), which is evidence of the presence of CFA in the nanocomposite. The image of $\mathrm{C}-\mathrm{TiO}_{2}$ (Figure $3 \mathrm{~b}(\mathrm{i})$ ) shows some agglomerated particles, and on the surface of these agglomerates, tiny ovoid-shaped particles of $\mathrm{C}-\mathrm{TiO}_{2}$ can be seen. 


\subsubsection{Energy Dispersive X-Ray Spectroscopy (EDS)}

EDS was used to identify the elements present in the prepared nanocomposite. The EDS spectra obtained are shown in Figure 4.

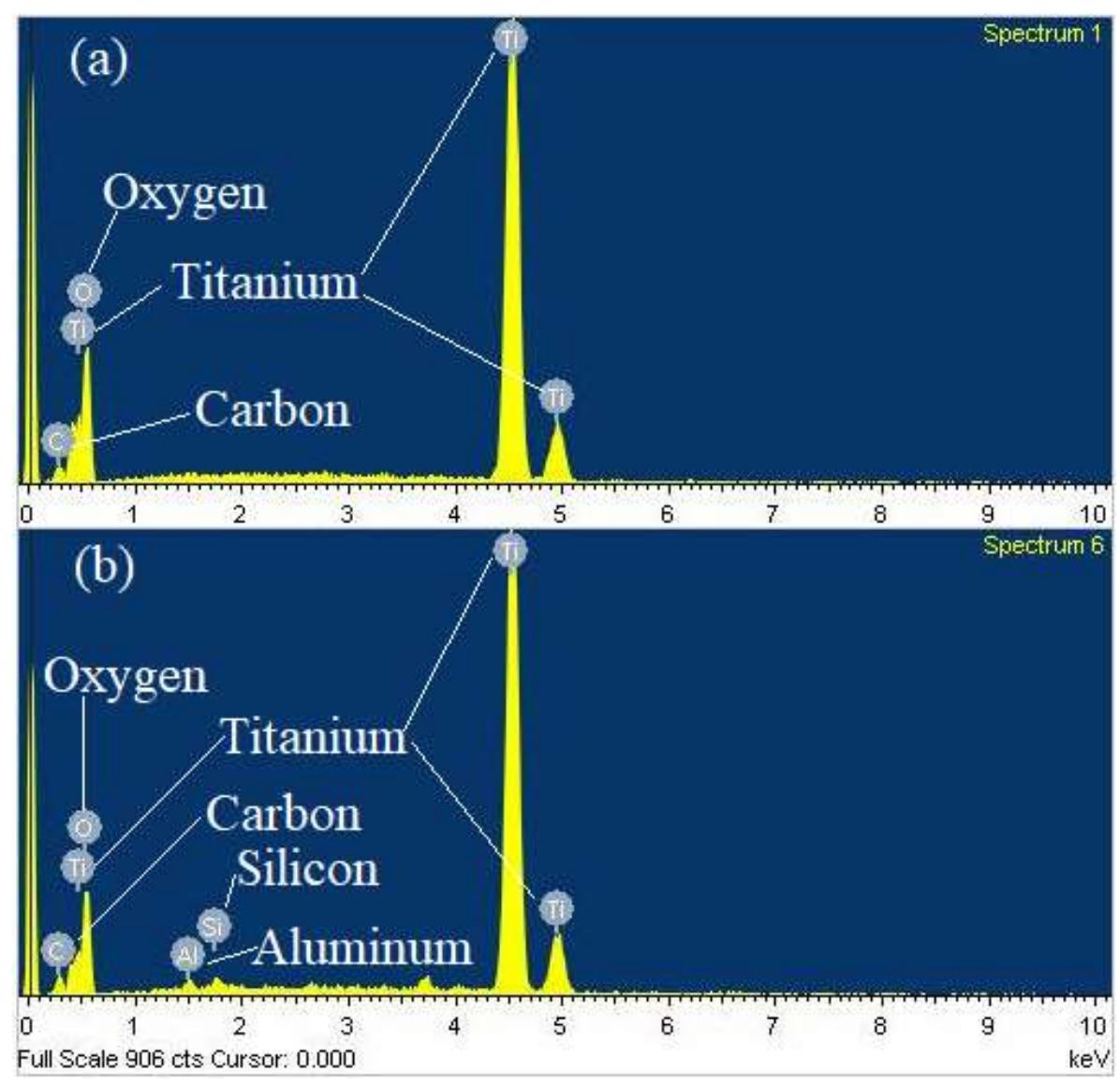

Figure 4. EDS spectra of (a) $\mathrm{C}-\mathrm{TiO}_{2}$ and (b) $\mathrm{C}-\mathrm{TiO}_{2}-\mathrm{CFA}$.

The EDS spectrum of $\mathrm{C}-\mathrm{TiO}_{2}$ (Figure 4a) shows the presence of the elements $\mathrm{C}$, $\mathrm{Ti}$, and $\mathrm{O}$. These elements are the constituents of $\mathrm{C}-\mathrm{TiO}_{2}$. In the spectrum for $\mathrm{C}-\mathrm{TiO}_{2}-\mathrm{CFA}$, the elements $\mathrm{C}, \mathrm{Ti}, \mathrm{O}, \mathrm{Al}$, and $\mathrm{Si}$ are present. The elements $\mathrm{Al}$ and $\mathrm{Si}$ are associated with CFA. The composition of CFA varies depending on the origin of the coal. The two spectra reveal the successful preparation of the $\mathrm{C}-\mathrm{TiO}_{2}-\mathrm{CFA}$ nanocomposite, since all the expected elements are present. Table 1 shows the estimated atomic weight percentages of the elements found to be present in the prepared $\mathrm{C}-\mathrm{TiO}_{2}-\mathrm{CFA}$ nanocomposite.

Table 1. Atomic weight percentages of the elements present in $\mathrm{C}-\mathrm{TiO}_{2}$ and $\mathrm{C}-\mathrm{TiO}_{2}-\mathrm{CFA}$.

\begin{tabular}{cccccc}
\hline Element (Atomic\%) & $\mathbf{C}$ & $\mathbf{O}$ & $\mathrm{Ti}$ & $\mathbf{A l}$ & $\mathbf{S i}$ \\
\hline $\mathrm{C}-T i O_{2}$ & 4.74 & 69.26 & 26.01 & - & - \\
$\mathrm{C}-T i O_{2}-\mathrm{CFA}$ & 4.22 & 65.97 & 28.98 & 0.37 & 0.46 \\
\hline
\end{tabular}

\subsubsection{Diffuse Reflectance Spectroscopy (DRS)}

Diffuse reflectance spectroscopy analysis was carried out to establish the absorption band edge of the prepared carbon doped nanocomposite. The DRS spectra obtained revealed that the prepared nanocomposite exhibited visible-light activity. The DRS data obtained were used to construct Tauc plots to establish the bandgap of the prepared composite photocatalysts 
(Figure 5).

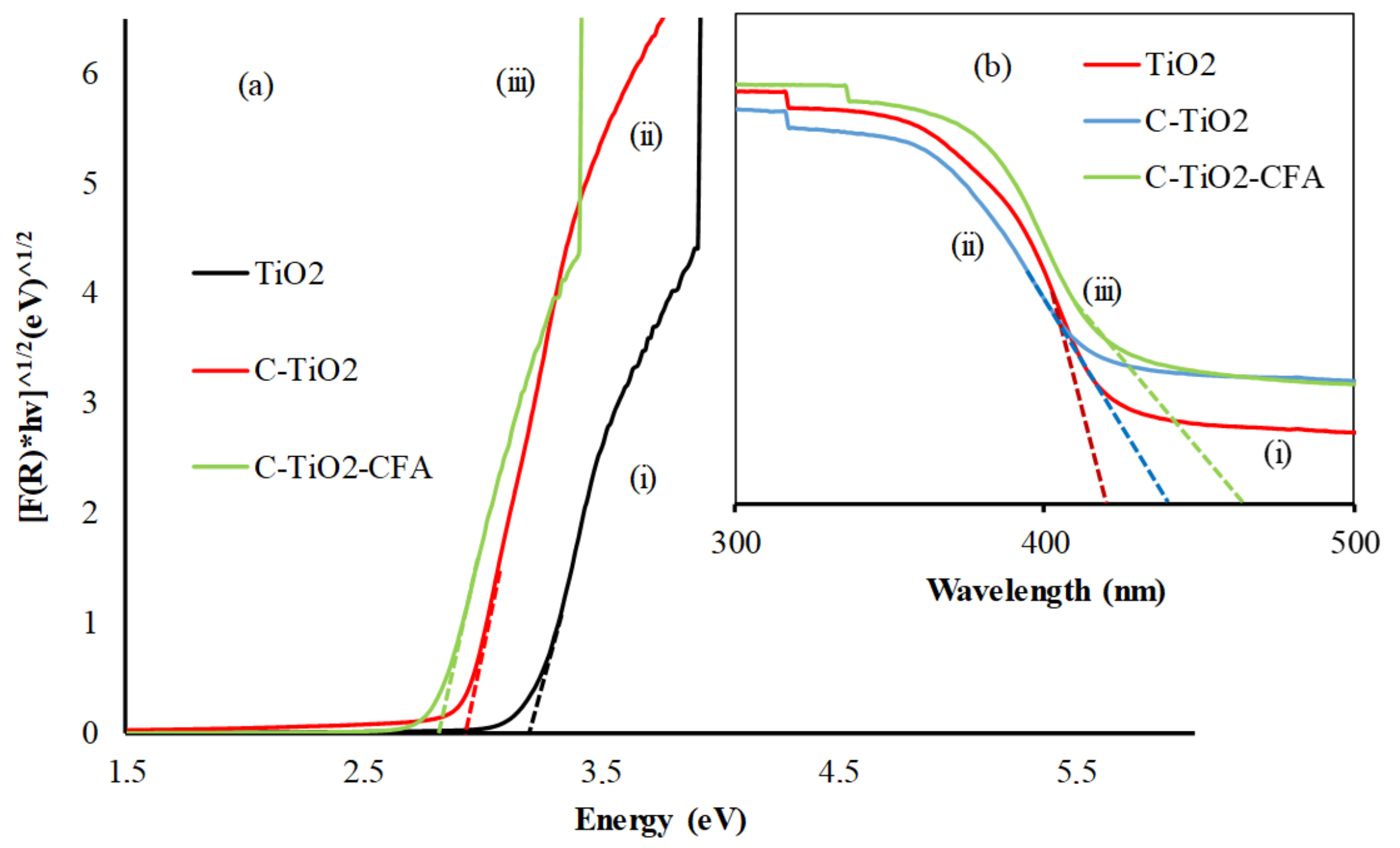

Figure 5. (a) Tauc plots for (i) $\mathrm{TiO}_{2}$, (ii) $\mathrm{C}-\mathrm{TiO}_{2}$, and (iii) $\mathrm{C}-\mathrm{TiO}_{2}-\mathrm{CFA}$; and (b) DRS for (i) $\mathrm{TiO}_{2}$, (ii) $\mathrm{C}-\mathrm{TiO}_{2}$, and (iii) $\mathrm{C}-\mathrm{TiO}_{2}-\mathrm{CFA}$. 
The Tauc plots obtained indicated that $\mathrm{C}-\mathrm{TiO}_{2}-\mathrm{CFA}$ had a reduced bandgap of $2.75 \mathrm{eV}$, while $\mathrm{C}-\mathrm{TiO}_{2}$ had a bandgap of $2.78 \mathrm{eV}$. The bandgap of $\mathrm{TiO}_{2}$ was found to be $3.19 \mathrm{eV}$, which is in close agreement with the literature. The introduction of trace amounts of carbon into the lattice structure of $\mathrm{TiO}_{2}$ dioxide through replacement of some of the lattice oxygen atoms managed to greatly reduce its bandgap. This allows the photocatalyst to absorb photons of light of a longer wavelength. The UV-light region is high energy but has a very narrow spectrum compared to the visible region, which is lower energy but has a much wider spectrum. Hence, a photocatalyst with a narrow bandgap will be able to utilize visible light and have high quantum efficiency, since it has a much wider spectrum (visible light constitutes about $40 \%$ of the solar spectrum). This would greatly increase the rate of pollutant photodegradation.

\subsection{Evaluation of Photocatalytic Activity}

The photocatalytic activity of the prepared $\mathrm{C}-\mathrm{TiO}_{2}-\mathrm{CFA} / \mathrm{PAN}$ membranes was evaluated in the degradation of dyes (methyl orange and golden yellow). The effect of parameters such as $\mathrm{pH}$, photocatalyst load on the membranes, and initial dye concentration were evaluated. Table 2 summarizes the sunlight intensities measured over a five-hour period, for different experiments.

\subsubsection{Photocatalyst Optimization}

In the preparation of $\mathrm{C}-\mathrm{TiO}_{2}-\mathrm{CFA} / \mathrm{PAN}$ photocatalytic membranes, the first stage was to optimize the amount of carbon dopant in the titanium dioxide photocatalyst. Methyl orange (MO) and golden yellow (GY) (azo dyes) were used in this preliminary study, to establish the best carbon dopant concentration. $\mathrm{TiO}_{2}$ photocatalysts doped with $2 \%, 4 \%$, and $6 \%$ carbon were prepared and evaluated in the photodegradation of MO and GY, under sunlight irradiation (Figure 6).

Table 2. Sunlight intensities recorded hourly over a five-hour period, for different experiments.

\begin{tabular}{ccccccc}
\hline Period (h) & $\mathbf{1}$ & $\mathbf{2}$ & $\mathbf{3}$ & $\mathbf{4}$ & $\mathbf{5}$ & \multirow{2}{*}{ Average Sunlight Intensity } \\
\cline { 1 - 5 } Experiment Type & \multicolumn{6}{c}{ Sunlight Intensity (lux) } \\
\cline { 1 - 5 } MOPS & 81,000 & 86,500 & 102,400 & 99,400 & 84,700 & 90,800 \\
GYPS & 101,650 & 105,900 & 110,400 & 108,250 & 106,800 & 106,600 \\
ECL & 98,950 & 109,600 & 115,850 & 110,200 & 108,400 & 108,600 \\
EIPC & 103,650 & 108,250 & 110,800 & 109,500 & 105,800 & 107,600 \\
EpH & 109,800 & 110,800 & 111,050 & 109,650 & 10,770 & 109,800 \\
ELS & 106,650 & 110,700 & 111,900 & 109,750 & 109,750 & 109,500 \\
\hline
\end{tabular}

MOPS = methyl orange dye preliminary studies, GYPS = golden yellow dye preliminary studies, ECL $=$ effect of catalyst load, EIPC $=$ effect of initial pollutant concentration, $\mathrm{EpH}=$ effect of $\mathrm{pH}$, and ELS = effect of light source. 

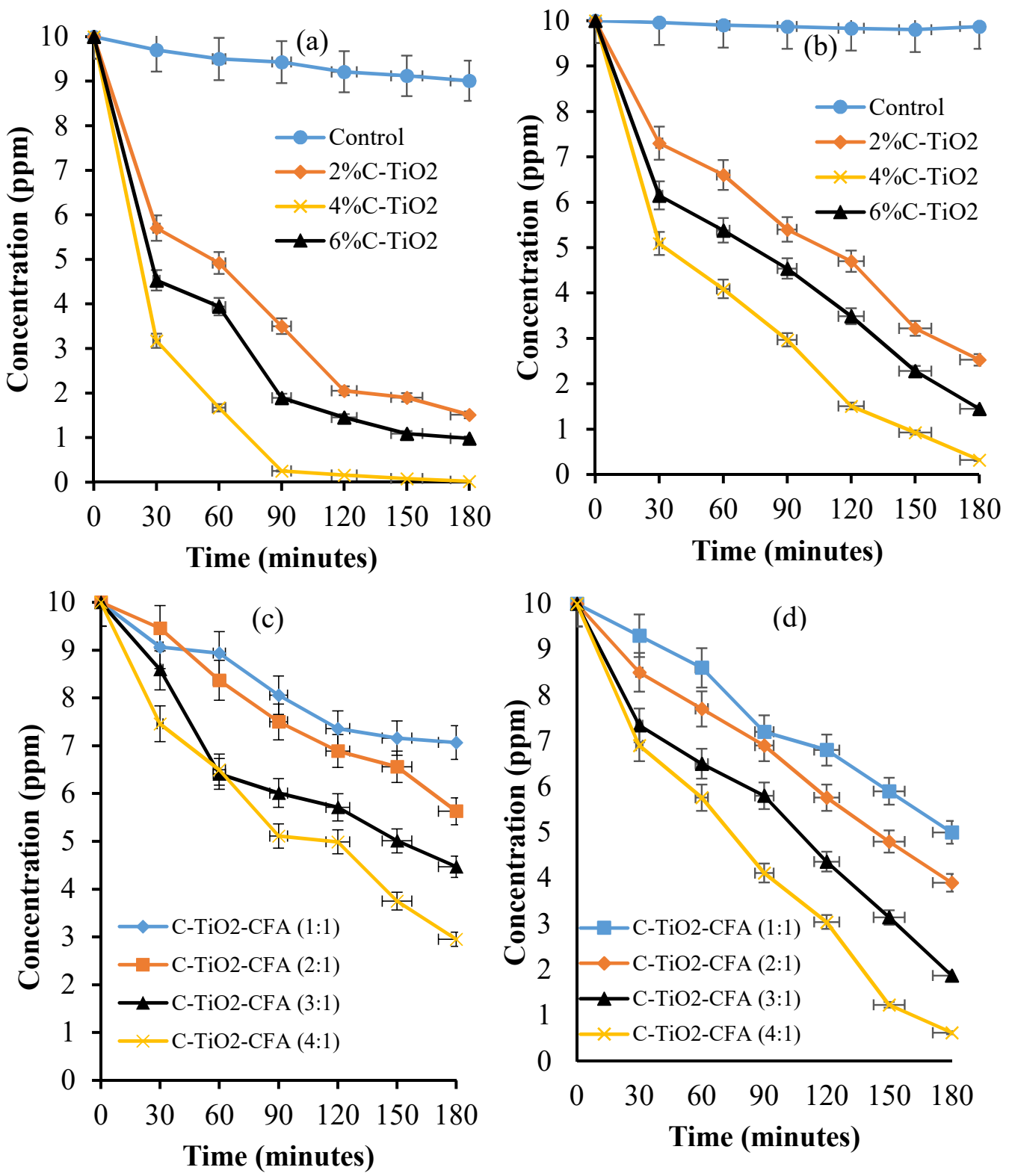

Figure 6. Degradation profiles of $\mathrm{MO}$ and GY, using (a,b) $\mathrm{C}-\mathrm{TiO}_{2}$ with different concentrations of carbon dopant $(2 \%, 4 \%$, and $6 \%)$; (c,d) different ratios of $\mathrm{C}_{-} \mathrm{TiO}_{2}$ : CFA $(4: 1,3: 1,2: 1$, and 1:1), respectively. A catalyst loading of $1 \mathrm{gL}^{-1}$ was used, and the volume of the dye polluted water was $100 \mathrm{~mL}$, with a concentration of 10 ppm. The average light intensities were 90,800 and 106,600 lux for MO and GY degradation experiments, respectively.

The rates of MO and GY dyes' photodegradation proceeded the fastest when using the photocatalyst doped with $4 \%$ carbon. According to the literature, when there is a higher carbon-dopant concentration, the number of electronic states in the bandgap is larger, leading to a reduction in bandgap [27]. The carbon-modified nanocomposite photocatalyst exhibited a bandgap of $2.75 \mathrm{eV}$. Degradation efficiencies of $99.8 \%$ and $96.8 \%$ were achieved in $180 \mathrm{~min}$ for MO and GY, respectively. A further increase in the carbon dopant, from $4 \%$ to $6 \%$, resulted in photodegradation efficiency drops of $9.6 \%$ and $11.3 \%$ for MO and GY, respectively. Using an excessive amount of dopant has been observed to negatively impact the photocatalytic efficiency of a photocatalyst [28]. The lowest rates of photodegradation were observed when using $2 \% \mathrm{C}-\mathrm{TiO}_{2}$ for both dyes. This photocatalyst achieved MO and GY dyes photodegradation efficiencies of $84.9 \%$ and $74.7 \%$, respectively, in $180 \mathrm{~min}$. Increasing the carbon dopant concentration from $2 \%$ to $4 \%$ improved the photodegradation efficiency of $\mathrm{TiO}_{2}$ greatly 
$\left(\approx 15 \%\right.$ and $22 \%$ for $\mathrm{MO}$ and GY). Moreover, $4 \% \mathrm{C}-\mathrm{TiO}_{2}$ was found to be the best photocatalyst (referred to as $\mathrm{C}-\mathrm{TiO}_{2}$ ) and was subsequently used to fabricate the $\mathrm{C}-\mathrm{TiO}_{2}-\mathrm{CFA}$ nanocomposite. Different ratios of $\mathrm{C}-\mathrm{TiO}_{2}$ : $\mathrm{CFA}$ were explored. The best ratio of $\mathrm{C}-\mathrm{TiO}_{2}$ to $\mathrm{CFA}$ was established as 4:1. This composite achieved photodegradation efficiencies of $70.5 \%$ and $93.8 \%$ in $180 \mathrm{~min}$. This photocatalyst was used in the preparation of the $\mathrm{C}-\mathrm{TiO}_{2}-\mathrm{CFA} / \mathrm{PAN}$ photocatalytic membrane.

\subsubsection{Effect of Photocatalyst Loading}

The effect of photocatalyst loading in the degradation of MO and GY was evaluated by varying the concentration of the $\mathrm{C}-\mathrm{TiO}_{2}-\mathrm{CFA}$ nanocomposite immobilized on the PAN membranes (Figure 7). Membranes with $0 \%, 1 \%, 1.5 \%$, and $2 \% \mathrm{C}-\mathrm{TiO}_{2}-\mathrm{CFA}$ were prepared. The pristine PAN membrane was used as the control of the experiment.
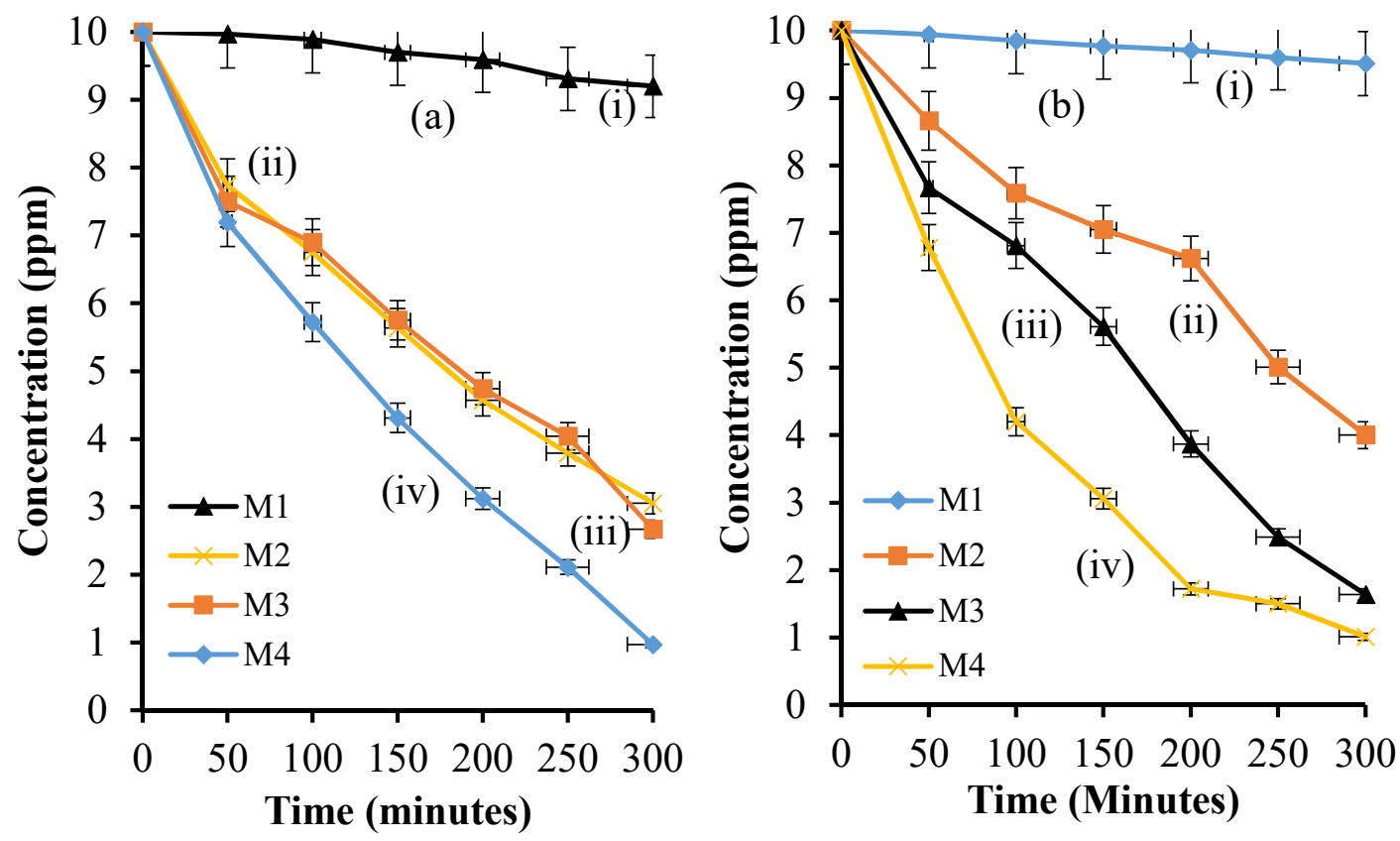

Figure 7. Photodegradation profiles for (a) MO and (b) GY, obtained using (i) pristine PAN (M1), (ii) $1 \% \mathrm{C}-\mathrm{TiO}_{2}-\mathrm{CFA} / \mathrm{PAN}$ membrane (M2), (iii) $1.5 \% \mathrm{C}-\mathrm{TiO}_{2}-\mathrm{CFA} / \mathrm{PAN}$ membrane (M3), and (iv) $2 \% \mathrm{C}-\mathrm{TiO}_{2}-\mathrm{CFA} / \mathrm{PAN}$ membrane (M4), under sunlight irradiation (108,600 lux of light intensity).

The photodegradation profiles obtained for MO and GY revealed that there was an increase in the rate of photodegradation with the increase in the catalyst load on the PAN membranes. The highest photodegradation rates were achieved by using $2 \% \mathrm{C}-\mathrm{TiO}_{2}-\mathrm{CFA} / \mathrm{PAN}$, which is $90.30 \%$ and $89.90 \%$ for MO and GY, respectively. A marginal change in concentration of MO and GY was observed in the control experiments. This change in concentration of the dyes can be attributed to adsorption. In comparison to powder photocatalyst, the performance of the immobilized photocatalyst is much lower. This is due to several factors, which include limitation on the photocatalyst load that can be immobilized without disturbing the membrane integrity and light penetration. In this study, the highest concentration that could be immobilized without affecting the membrane integrity was $2 \%$. Despite the drop in photocatalytic activity, the advantage of immobilization of photocatalyst is to cut on costs involved in the recovery of spent nanoparticles and allow for easier recycling of the photocatalyst. The photodegradation efficiencies achieved with the immobilized photocatalysts in the degradation of MO and GY were very reasonable. 


\subsubsection{Effect of Initial Pollutant Concentration}

The effect of initial MO and GY dye concentration on the rate of photodegradation was evaluated (Figure 8). The initial MO and GY were varied in the range of 10 to $30 \mathrm{ppm}$.
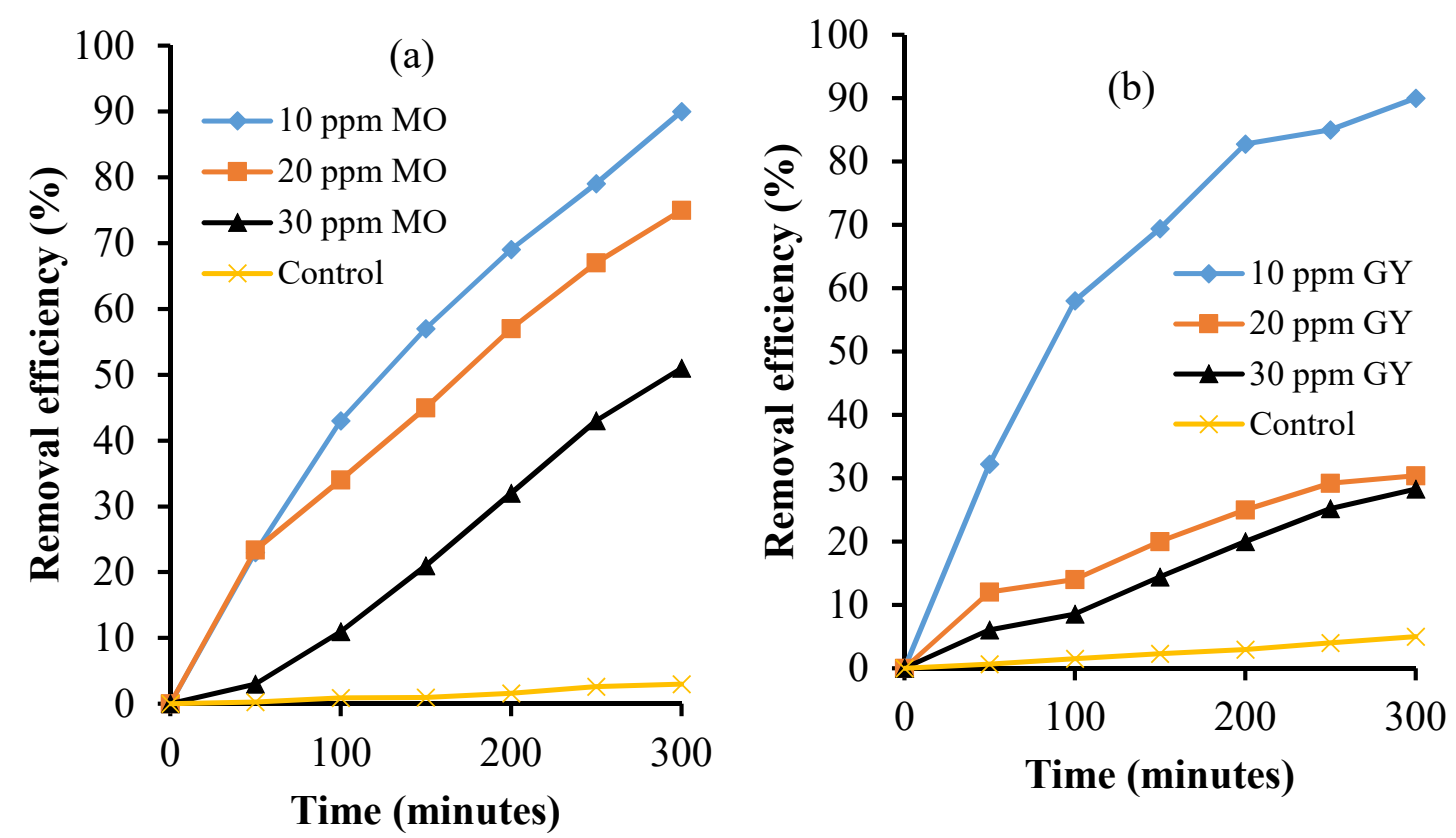

Figure 8. Photodegradation profiles of (a) MO and (b) GY at different initial concentrations obtained by using $2 \% \mathrm{C}-\mathrm{TiO}_{2}-\mathrm{CFA} / \mathrm{PAN}$ membrane under sunlight irradiation (107,600 lux of light intensity), at ambient $\mathrm{pH}$.

Using initial MO and GY dye concentrations of $10 \mathrm{ppm}$, a 90\% removal efficiency was attained for either dye. As soon as the dye concentrations were increased to $20 \mathrm{ppm}$, there was a dramatic change in the rates of photodegradation. The photodegradation efficiencies dropped to $75 \%$ and $30.40 \%$ for $\mathrm{MO}$ and GY, respectively. A further increase of the initial dye concentrations to $30 \mathrm{ppm}$ resulted in a $39 \%$ and a $61.70 \%$ drop in photocatalytic activity for MO and GY dyes, respectively. The two azo dyes have different chemical structures, hence the huge difference in how they affect light passing through the dye solutions. This huge drop in photocatalytic activity can be ascribed to the effects of the drop in light penetration as dye concentration increases, leading to low quantum efficiency. The change in dye concentration in the control experiments is attributed to adsorption of dye on the PAN membranes.

\subsubsection{Effect of $\mathrm{pH}$ on Rate of Photodegradation}

The effect of $\mathrm{pH}$ on the rate of dye photodegradation was evaluated, using the $2 \% \mathrm{C}-\mathrm{TiO}_{2}-\mathrm{CFA} / \mathrm{PAN}$ membrane photocatalyst, initial dye concentration of $10 \mathrm{ppm}$ for MO and GY, and sunlight irradiation. The results obtained are shown in Figure 9. 

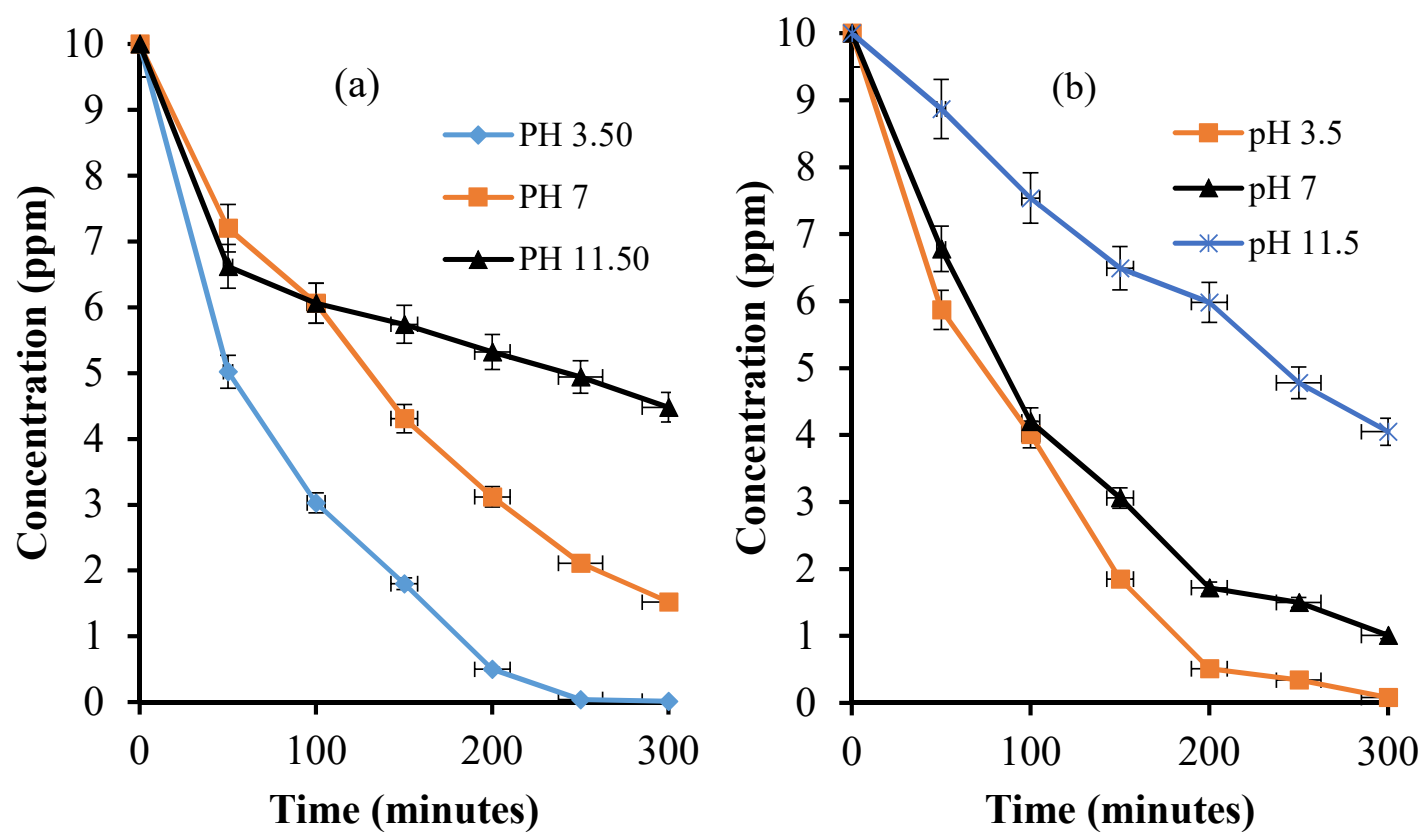

Figure 9. Photodegradation profiles of (a) MO and (b) GY dyes obtained by using the $2 \% \mathrm{C}-\mathrm{TiO}_{2}$-CFA/PAN photocatalytic membrane under sunlight irradiation (109,800 lux of light intensity), while varying $\mathrm{pH}$.

The $2 \% \mathrm{C}-\mathrm{TiO}_{2}-\mathrm{CFA} / \mathrm{PAN}$ photocatalytic membrane achieved $\mathrm{MO}$ and $\mathrm{GY}$ removal efficiencies of $99.86 \%$ and $99.20 \%$ at $\mathrm{pH} 3.5$. The findings show that the photocatalyst exhibited very high photocatalytic activity under acidic conditions. At basic $\mathrm{pH}$, the removal efficiencies of MO and GY dyes were $55.20 \%$ and $59.50 \%$. This is a clear indication that $\mathrm{pH}$ affects the surface characteristics of the photocatalyst, as well as the dye structure and surface characteristics. Under acidic conditions, the surface of $\mathrm{TiO}_{2}$-based photocatalyst is positively charged. The azo dyes (MO and GY) exhibit a mono-protonated zwitter ionic structure under acidic conditions. This enhances the adsorption of the dyes on the photocatalyst surface, leading to an increased rate of photodegradation. Under basic conditions, there is loss of the azo dye double-bond conjugation and a proton, leading to the rearrangement of the molecules to a negatively charged state. Owing to excess anions in solution, there will be repulsion of the negatively charged dye molecules by the negatively charged photocatalyst. These conditions lead to a reduced rate of dye photodegradation.

\subsubsection{Effect of Light Source on Rate of Photodegradation}

The effect of light source to activate the $2 \% \mathrm{C}-\mathrm{TiO}_{2}-\mathrm{CFA} / \mathrm{PAN}$ membrane photocatalyst in the photodegradation of MO and GY was investigated by using sunlight (109,500 lux of light intensity) and strict UV-light irradiation (4650 lux of light intensity). The experiments were carried out by using the optimum conditions established (10 ppm dye, pH 3.5), and the results are shown in Figure 10. 

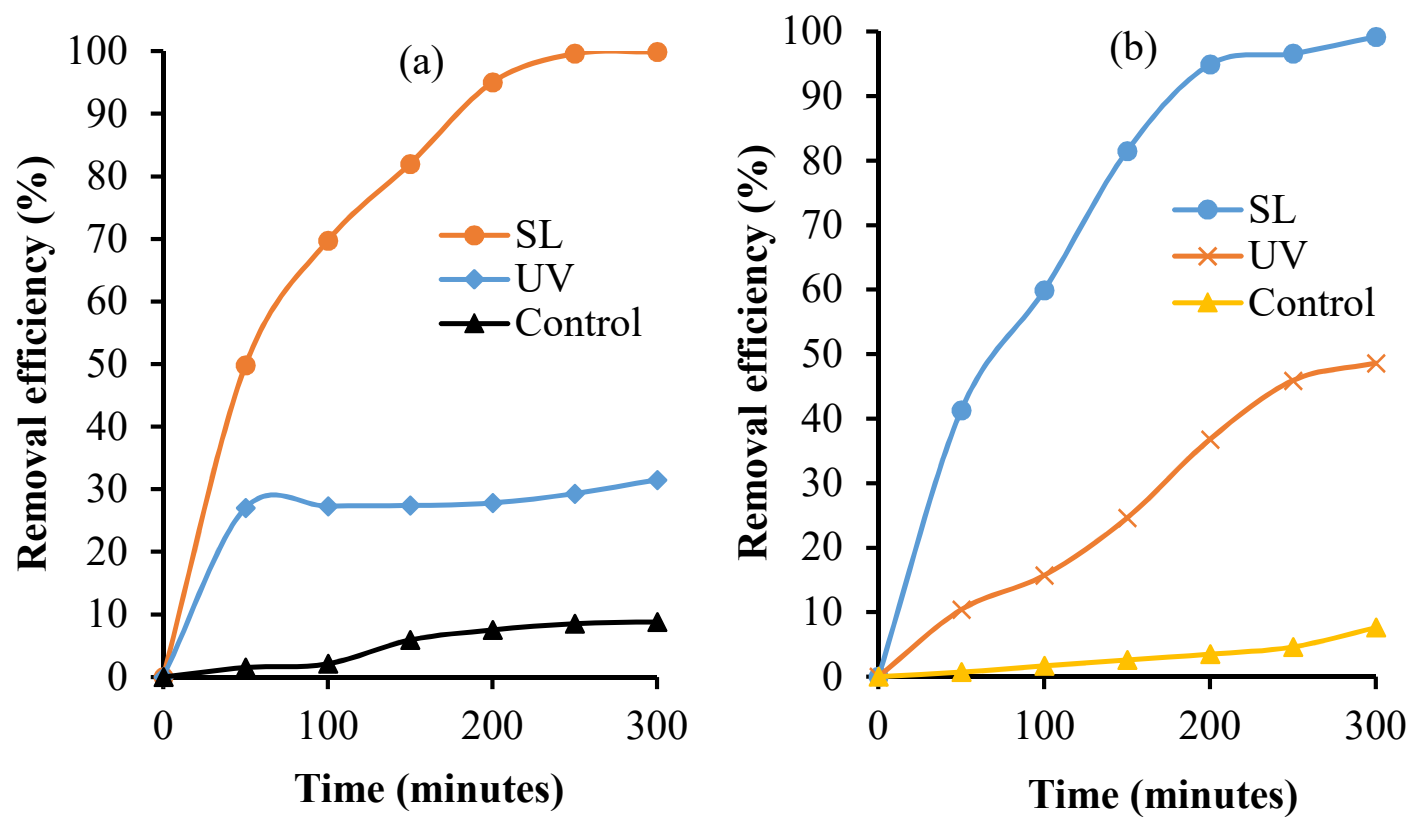

Figure 10. Photodegradation profiles of (a) MO and (b) GY under sunlight (SL) and strict ultraviolet-light (UV) irradiation, using the $2 \% \mathrm{C}-\mathrm{TiO}_{2}-\mathrm{CFA} / \mathrm{PAN}$ membrane photocatalyst at $\mathrm{pH} 3.5$.

The highest degradation efficiencies $(99.86 \%$ and $99.20 \%)$ were achieved under sunlight irradiation (109,500 lux of light intensity) for MO and GY dyes, respectively. Modifying the photocatalyst with carbon dopant allowed it to absorb visible light, which is a much wider spectrum, resulting in high quantum efficiency. Under strict UV-light irradiation (4650 lux of light intensity), removal efficiencies of $31.50 \%$ and $48.60 \%$ were achieved in $300 \mathrm{~min}$ for MO and GY dyes, respectively. The UV-light spectrum only accounts for about $5 \%$ of the solar spectrum; hence, there are higher chances of light reaching the catalyst surface if it exhibits visible light activity, leading to higher rates of pollutant photodegradation, as observed in this study. The prepared photocatalyst proved to be very efficient in the photodegradation of dyes in water; hence, reusability studies were carried out to determine if the catalyst would maintain high photoactivity. The results are shown in Table 3.

Table 3. Reusability cycles in the photodegradation of $\mathrm{MO}$ and GY, using $2 \% \mathrm{C}-\mathrm{TiO}_{2}-\mathrm{CFA} / \mathrm{PAN}$.

\begin{tabular}{cccc}
\hline - & Initial & Cycle 1 & Cycle 2 \\
\hline MO degradation efficiency (\%) & 99.86 & 99.90 & 99.88 \\
GY degradation efficiency (\%) & 99.20 & 98.90 & 98.50 \\
\hline
\end{tabular}

The findings of the photocatalytic membrane reusability in the degradation of MO and GY dyes revealed that there was no significant change in the performance of the photocatalyst over three cycles. This implies that the $2 \% \mathrm{C}-\mathrm{TiO}_{2}-\mathrm{CFA} / \mathrm{PAN}$ membrane photocatalyst can efficiently and cost-effectively be used in the depollution of water contaminated with textile dyes. The findings of this study are a huge contribution toward the commercial use of modified $\mathrm{TiO}_{2}$ photocatalysts in water treatment.

\section{Discussion}

Photocatalytic membranes of C- $\mathrm{TiO}_{2}-\mathrm{CFA} / \mathrm{PAN}$ were prepared and characterized, using FTIR, XRD, SEM-EDS, and DRS. FTIR analysis confirmed the presence of functional groups expected on both $\mathrm{C}-\mathrm{TiO}_{2}-\mathrm{CFA}$ and PAN. The findings are also in agreement with the literature [26,29]. XRD confirmed that the $\mathrm{TiO}_{2}$ present in the $\mathrm{C}-\mathrm{TiO}_{2}$-CFA nanocomposite was predominantly in the anatase phase, which is reported to exhibit the higher photocatalytic activity than other phases [21]. SEM analysis of the $\mathrm{C}-\mathrm{TiO}_{2}$-CFA/PAN membranes confirmed that they had an asymmetric structure. EDS elemental 
analysis confirmed the presence of the major elements expected in the prepared composite. The Scherrer equation was used to estimate particle size. The $\mathrm{C}-\mathrm{TiO}_{2}$-CFA nanocomposites had a particle size of $11.62 \mathrm{~nm}$ (BET surface area $=114.02 \mathrm{~m}^{2} / \mathrm{g}$ ). Small particles present a very large surface area for reactions to take place, and in the case of nanosized photocatalyst, it means there will be more active sites presented. All the findings confirmed successful preparation of the photocatalytic nanocomposite incorporated polymer membranes. The performance of the $\mathrm{C}-\mathrm{TiO}_{2}-\mathrm{CFA} / \mathrm{PAN}$ membrane photocatalyst was evaluated in the photodegradation of textile dyes MO and GY. Several parameters (effects of carbon dopant concentration, ratio of $\mathrm{C}-\mathrm{TiO}_{2}$ to $\mathrm{CFA}$, photocatalyst load on membrane support, $\mathrm{pH}$ of solution, initial pollutant concentration, and light source used in photocatalyst activation) were evaluated in the process of optimizing the performance of this novel photocatalyst. The study established that the best conditions were a carbon dopant concentration of $4 \%$, a C- $-\mathrm{TiO}_{2}$ to CFA ratio of $4: 1$, a photocatalyst load of $2 \%$ on the PAN membrane, and a solution $\mathrm{pH}$ of 3.5 . The prepared $2 \% \mathrm{C}-\mathrm{TiO}_{2}-\mathrm{CFA} / \mathrm{PAN}$ membrane photocatalyst exhibited visible-light activity, and this observation was supported by DRS results, which confirmed a reduced bandgap of $2.75 \mathrm{eV}$ for C-TiO ${ }_{2}-\mathrm{CFA}$ after carbon doping. Carbon doping is known to introduce mid-band states which will allow utilization of low-energy light in the photocatalytic process [19]. The ability of the carbon-modified $\mathrm{TiO}_{2}$ photocatalyst membrane to utilize visible light results in high quantum yield, since the visible-light region is a much wider spectrum (about $40 \%$ of the solar spectrum), increasing the chances of photons of light of the correct wavelength to strike the surface of the photocatalyst, activating it $[27,28]$. The performance of the photocatalyst was also evaluated under both sunlight and strict UV light. Very high efficiencies were achieved in the photodegradation of MO and GY under sunlight, compared to strict UV light irradiation. In a related study, other researchers prepared $\mathrm{TiO}_{2}$ supported on polymeric disposals and applied them in the treatment of dye-factory effluent. They achieved removal efficiencies of $39 \%$ and $42 \%$ for factory 1 and factory 2 wastewater samples [30]. In another study, a $\mathrm{TiO}_{2} / \mathrm{Ag}$ binary nanocomposite was grafted onto poly (styrene sulfonic acid) and used in the removal of methyl arrange in water. They reported enhanced performance under visible-light irradiation which was attributed to the plasmon effect. These findings suggest that polymeric materials have great potential as photocatalyst support in water treatment [31]. To generate an efficient water treatment technology, future studies will examine the suitability of the prepared membrane as filtration media. The influence of the $\mathrm{C}-\mathrm{TiO}_{2}-\mathrm{CFA}$ nanocomposite on membrane permeability and its antifouling properties will be investigated. Antimicrobial studies will also be carried out to determine the potential of the $\mathrm{C}-\mathrm{TiO}_{2}-\mathrm{CFA} / \mathrm{PAN}$ membrane as a disinfection method during the water treatment process. Future studies can also focus on the suitability of the $\mathrm{C}-\mathrm{TiO}_{2}-\mathrm{CFA} / \mathrm{PAN}$ membrane for use in the photoreductive removal of heavy-metal pollutants in water and wastewater.

\section{Materials and Methods}

\subsection{Materials}

The following chemicals and materials were used in this study: titanium(IV) butoxide (97\% Sigma-Aldrich, Darmstadt, Germany), methanol (99.8\%, Associated Chemical Enterprises, Johannesburg, South Africa), ethanol (99.9\% Ibhayi Lab Supplies, Port Elizabeth, South Africa), glucose (Merck, Germiston, South Africa), hydrochloric acid (32\%, Associated Chemical Enterprises, Johannesburg, South Africa) poly(acrylonitrile) powder (PAN) $\left(\mathrm{M}_{\mathrm{w}} 150,000\right.$, Merck, Germiston, South Africa), N,N'-dimethylacetamide (99.5\%, Sigma-Aldrich, Darmstadt, Germany), methyl orange (85\%, Merck, Germiston, South Africa), golden yellow (85\%, Merck, Germiston, South Africa), ammonia solution (25\% Associated Chemical Enterprises, Johannesburg, South Africa), and coal fly ash (Eskom Power Plant, Kempton Park, South Africa). 


\subsection{Methods}

\subsubsection{Pretreatment of Coal Fly Ash}

Raw coal fly ash was washed with distilled water, under mechanical stirring (at a ratio of $1 \mathrm{~g}$ CFA: $10 \mathrm{~mL}$ water), at room temperature $\left(20-22^{\circ} \mathrm{C}\right)$, for $48 \mathrm{~h}$, until constant $\mathrm{pH}$ and conductivity were achieved. The CFA was then dried in the temperature range of 105 to $115^{\circ} \mathrm{C}$, and then sieved [32].

\subsubsection{Synthesis of Carbon-Doped $\mathrm{TiO}_{2}$-Coal Fly Ash Nanocomposite}

The $\mathrm{C}-\mathrm{TiO}_{2}$-CFA nanocomposite was prepared by using a method by Behnajady and co-workers, with some modifications [33]. Titanium (IV) butoxide was dissolved in methanol, in a 1:1 ratio, and then sonicated in an ultrasonic bath. The titanium solution obtained was placed in a 3-necked round-bottomed flask, and deionized water was added, dropwise, under reflux. After $30 \mathrm{~min}$ of reflux at $80^{\circ} \mathrm{C}$, glucose was added as the carbon source, and the process continued for $1 \mathrm{~h}$. Different percentages of the carbon dopant were added, to optimize the doping process (i.e., $2 \%, 4 \%$, and $6 \%$ carbon). Then, $4 \%$ carbon was established as the optimum dopant concentration, and the synthesis procedure was completed using this ratio. Pretreated coal fly ash was then added to the reaction vessel, and the reflux process was maintained for $1 \mathrm{~h}$ and $30 \mathrm{~min}$. Different ratios of CFA to the carbon-doped titanium sol were used (1:1, 1:2, 1:3, and 1:4) to optimize the resultant nanocomposite photocatalyst. The resultant products were dried in an oven, at $60^{\circ} \mathrm{C}$, and subsequently calcinated at $550{ }^{\circ} \mathrm{C}$, to transform amorphous titanium dioxide to predominantly anatase phase. The resultant photocatalysts were tested in the photodegradation of dye wastewater, to establish the best catalyst that would be immobilized on polymeric membranes. The test results showed that the photocatalyst with $\mathrm{C}-\mathrm{TiO}_{2}$ to CFA ratio of 4:1 exhibited the highest activity.

\subsubsection{Immobilization of $\mathrm{C}-\mathrm{TiO}_{2}$-CFA Nanocomposite on PAN}

Different concentrations of the $\mathrm{C}-\mathrm{TiO}_{2}-\mathrm{CFA}$ nanocomposite were immobilized on poly(acrylonitrile) membranes, to establish the optimum catalyst load. The phase-inversion technique was used in the preparation of the asymmetric membranes [34]. In a typical experiment, $1.5 \mathrm{~g}$ of PAN were dissolved in $7 \mathrm{~mL}$ of $\mathrm{N}, \mathrm{N}^{\prime}$-dimethylacetamide, under stirring in a beaker. When the PAN was completely dissolved, different concentrations of the optimized photocatalyst $\left(1 \%, 1.5 \%\right.$, and $\left.2 \% \mathrm{C}-\mathrm{TiO}_{2}-\mathrm{CFA}\right)$ were added into separate beakers with the dissolved PAN, and then they were homogenized through stirring and sonication. When the polymer solutions achieved the desired viscosity, they were then cast on cylindrical glass plates with a diameter of $7 \mathrm{~cm}$. The polymer solutions were evenly spread and aged for $10 \mathrm{~min}$ in open air, to partially evaporate some of the solvent. The glass plates were then placed in a coagulation bath with a water-to-ethanol ratio of 5:1, respectively. The resulting photocatalytic PAN membranes $\left(\mathrm{C}-\mathrm{TiO}_{2}-\mathrm{CFA} / \mathrm{PAN}\right)$ were then rinsed and stored in deionized water, for further testing.

\subsection{Characterization}

A PerkinElmer Fourier transform infrared (FTIR) spectrometer (6700FTIR, Nicolet, Waltham, MA, USA) was used to identify the functional groups present on the prepared nanocomposite and the photocatalytic polymer membranes. The FTIR spectra were obtained in the range of $4000-400 \mathrm{~cm}^{-1}$. The morphologies and elemental compositions of the nanocomposites and the photocatalytic PAN membranes were probed, using a Tescan Vega 3 scanning electron microscope (Tescan Analytics, Fuveau, France) with energy dispersive X-ray spectroscopy (SEM-EDS). A PANalytical X'Pert PRO X-ray Diffraction (XRD) instrument (Malvern Panalytical Ltd., Malvern, UK) was used to probe the crystallinity of the fabricated photo-catalysts, as well as establish the different phases present in the $\mathrm{C}-\mathrm{TiO}_{2}$-CFA. 


\subsection{Evaluation of Photocatalytic Efficiency}

The photocatalytic activity of the as-prepared $\mathrm{C}-\mathrm{TiO}_{2}-\mathrm{CFA}-\mathrm{PAN}$ nanocomposite membranes was evaluated under visible light irradiation, using methyl orange (MO) and golden yellow (GY) dyes as target organic pollutants. MO and GY dye solutions $(100 \mathrm{~mL})$ were placed into the reactors containing the $\mathrm{C}-\mathrm{TiO}_{2}$-CFA/PAN membranes, with different photocatalyst loadings. Before exposure to sunlight, samples were placed in a darkroom for $1 \mathrm{~h}$, to allow equilibration. Each reactor was exposed to sunlight for a period of $5 \mathrm{~h}$, and aliquots were collected at $50 \mathrm{~min}$ intervals, to follow the changes in concentration, using UV-Vis spectroscopy (PerkinElmer Lambda 45) (PerkinElmer, Inc., Waltham, MA, USA). Every experiment was done in triplicate, to ensure reproducibility. The parameters investigated were effect of $\mathrm{pH}$, photocatalyst loading, and initial dye concentration. Hydrochloric acid and sodium hydroxide solutions were used to adjust $\mathrm{pH}$. The sunlight intensity was measured hourly, using a lux meter (LT Lutron L × 10/A digital lux meter) (Lutron Electronic Enterprise CO., Ltd., Taipei, Taiwan). To ensure consistency of the sunlight source, experiments were only carried out on clear sunny days (summer months-October 2019 to December 2019), between 9:00 h and 14:00 h, when the solar intensity approaches its peak. The sunlight intensities reported here are averages recorded for the duration of the experiments (Table 2). All strict UV-light experiments were carried out in a dark room, using a Camag lamp $(50 / 60 \mathrm{~Hz}, 40 \mathrm{~W}$ ) (Bruno Steiner Lab Consultancy, Johannesburg, South Africa) capable of providing $\mathrm{UV}_{254}$ and $\mathrm{UV}_{366}$. The lamp was placed at a distance of $15 \mathrm{~cm}$ above the reactor.

\section{Conclusions}

With the advent of increasing environmental and water resource pollution, this study set out to develop an improved water treatment technology and, at the same time, provide a solution to avert the challenges associated with the accumulation of coal fly ash in the environment. The current study aimed at improving the photocatalytic properties of titanium dioxide by combining it with coal fly ash, which is desired for its high adsorption properties. A nanocomposite of $\mathrm{C}-\mathrm{TiO}_{2}$-CFA was successfully prepared and immobilized on a poly(acrylonitrile) membrane, to avoid challenges associated with post-recovery of fine nanoparticles after water treatment. XRD confirmed the presence of the anatase phase of $\mathrm{TiO}_{2}$, which exhibits the highest photocatalytic activity. The reduced bandgap of $2.75 \mathrm{eV}$ after carbon doping and large surface area $\left(114.02 \mathrm{~m}^{2} / \mathrm{g}\right)$ of the nanocomposite allowed it to achieve high photodegradation efficiencies ( $99.86 \%$ and $99.2 \%$ for MO and GY respectively). The optimum conditions established were a photocatalyst load of $2 \%$ on the PAN membrane, an initial pollutant concentration of $10 \mathrm{ppm}$, and a $\mathrm{pH}$ of 3.5. Poly(acrylonitrile) membranes proved to be suitable matrix for the prepared photocatalyst, since they allowed the photocatalytic process to proceed at reasonable rates, for optimal performance. This study revealed that it is necessary to establish optimum operational conditions for a new catalyst to attain efficiency in the water treatment process. The prepared novel photocatalytic membranes showed great potential as a solar-driven method for depolluting wastewater containing textile dyes. Sunlight is an abundant natural resource that can greatly reduce the energy requirements of a water treatment process. If left untreated, textile dyes deteriorate the water's quality and may cause a host of negative health effects; hence, the water treatment technology presented here is capable of averting such effects, through the efficient depollution of water.

Author Contributions: Conceptualization, H.H.M. and D.M.K.; methodology, A.M.; analysis of results, R.T.T.; investigation, A.M.; resources, D.M.K.; data curation, R.T.T. and A.M.; writing—original draft preparation, A.M.; writing-review and editing, H.H.M. and R.T.T.; visualization, P.N.; supervision, D.M.K., H.H.M., and P.N.; project administration, H.H.M.; funding acquisition, H.H.M. All authors have read and agreed to the published version of the manuscript.

Funding: This research was funded by the National Research Foundation of South Africa, grant number 112013 and the Sasol Inzalo Foundation.

Acknowledgments: I would like to thank T. Mcako and K. Tshapu for assistance with UV-Vis, FTIR, TGA, PL, and XRD analyses.

Conflicts of Interest: The authors declare no conflict of interest. 


\section{References}

1. Yuan, F.; Wei, Y.D.; Gao, J.; Chen, W. Water crisis, environmental regulations and location dynamics of pollution-intensive industries in China: A study of the Taihu Lake watershed. J. Clean. Prod. 2019, 216, 311-322. [CrossRef]

2. Chen, L.; Caro, F.; Corbett, C.J.; Ding, X. Estimating the environmental and economic impacts of widespread adoption of potential technology solutions to reduce water use and pollution: Application to China's textile industry. Environ. Impact Assess. Rev. 2019, 79, 106293. [CrossRef]

3. Chen, L.; Wang, L.; Wu, X.; Ding, X. A process-level water conservation and pollution control performance evaluation tool of cleaner production technology in textile industry. J. Clean. Prod. 2017, 143, 1137-1143. [CrossRef]

4. Liu, B.; Wu, J.; Cheng, C.; Tang, J.; Khan, M.F.S.; Shen, J. Identification of textile wastewater in water bodies by fluorescence excitation emission matrix-parallel factor analysis and high-performance size exclusion chromatography. Chemosphere 2019, 216, 617-623. [CrossRef]

5. Wang, S.; Zhang, X.; Jiang, C.; Jiang, X.; Qiao, J. Facile preparation of Janus polymer film and application in alleviating water crisis. Mater. Chem. Phys. 2020, 240, 122256. [CrossRef]

6. Hossain, L.; Sarker, S.K.; Khan, M.S. Evaluation of present and future wastewater impacts of textile dyeing industries in Bangladesh. Environ. Dev. 2018, 26, 23-33. [CrossRef]

7. Basiglini, E.; Pintore, M.; Forni, C. Effects of treated industrial wastewaters and temperatures on growth and enzymatic activities of duckweed (Lemna minor L.). Ecotoxicol. Environ. Saf. 2018, 153, 54-59. [CrossRef]

8. Baca, M.; Wenelska, K.; Mijowska, E.; Kaleńczuk, R.J.; Zielińska, B. Physicochemical and photocatalytic characterization of mesoporous carbon/titanium dioxide spheres. Diam. Relat. Mater. 2020, 101, 107551. [CrossRef]

9. Kiwaan, H.A.; Atwee, T.M.; Azab, E.A.; El-Bindary, A.A. Photocatalytic degradation of organic dyes in the presence of nanostructured titanium dioxide. J. Mol. Struct. 2020, 1200, 127115. [CrossRef]

10. Mungondori, H.H.; Ramujana, S.; Katwire, D.M.; Taziwa, R.T. Synthesis of a novel visible light responsive $\gamma-\mathrm{Fe}_{2} \mathrm{O}_{3} / \mathrm{SiO}_{2} / \mathrm{C}-\mathrm{TiO}_{2}$ magnetic nanocomposite for water treatment. Water Sci. Technol. 2018, 78, $2500-2510$. [CrossRef]

11. Sang, N.X.; Huong, P.T.L.; Thy, T.T.M.; Dat, P.T.; Minh, V.C.; Tho, N.H. Crystalline deformation and photoluminescence of titanium dioxide nanotubes during in situ hybridization with graphene: An example of the heterogeneous photocatalyst. Superlattices Microstruct. 2018, 121, 9-15. [CrossRef]

12. Zhang, D. Heterogeneous photocatalytic removal and reaction kinetics of Rhodamine-B dye with Au loaded $\mathrm{TiO}_{2}$ nanohybrid catalysts. Pol. J. Chem. Technol. 2012, 14, 42-48. [CrossRef]

13. Tsai, C.-Y.; Liu, C.-W.; Fan, C.; Hsi, H.-C.; Chang, T.-Y. Synthesis of a $\mathrm{SnO}_{2} / \mathrm{TNT}$ heterojunction nanocomposite as a high-performance photocatalyst. J. Phys. Chem. C 2017, 121, 6050-6059. [CrossRef]

14. Gayathri, S.; Kottaisamy, M.; Ramakrishnan, V. Facile microwave-assisted synthesis of titanium dioxide decorated graphene nanocomposite for photodegradation of organic dyes. AIP Adv. 2015, 5, 127219. [CrossRef]

15. Chen, H.-W.; Hong, C.-Y.; Kung, C.-W.; Mou, C.-Y.; Wu, K.C.-W.; Ho, K.-C. A gold surface plasmon enhanced mesoporous titanium dioxide photoelectrode for the plastic-based flexible dye-sensitized solar cells. J. Power Sources 2015, 288, 221-228. [CrossRef]

16. Inamuddin. Xanthan gum/titanium dioxide nanocomposite for photocatalytic degradation of methyl orange dye. Int. J. Biol. Macromol. 2019, 121, 1046-1053. [CrossRef]

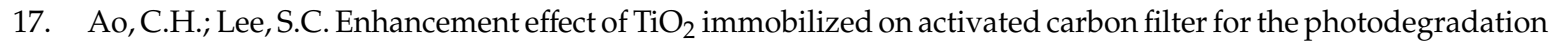
of pollutants at typical indoor air level. Appl. Catal. B Environ. 2003, 44, 191-205. [CrossRef]

18. Rahimpour, A.; Madaeni, S.S.; Taheri, A.H.; Mansourpanah, Y. Coupling $\mathrm{TiO}_{2}$ nanoparticles with UV irradiation for modification of polyethersulfone ultrafiltration membranes. J. Membr. Sci. 2008, 313, 158-169. [CrossRef]

19. Yan, B.; Zhou, J.; Liang, X.; Song, K.; Su, X. Facile synthesis of flake-like $\mathrm{TiO}_{2} / \mathrm{C}$ nano-composites for photocatalytic $\mathrm{H}_{2}$ evolution under visible-light irradiation. Appl. Surf. Sci. 2017, 392, 889-896. [CrossRef]

20. Chao, K.J.; Cheng, W.Y.; Yu, T.H.; Lu, S.Y. Large enhancements in hydrogen production of $\mathrm{TiO}_{2}$ through a simple carbon decoration. Carbon 2013, 62, 69-75. [CrossRef]

21. Meng, A.; Zhang, J.; Xu, D.; Cheng, B.; Yu, J. Enhanced photocatalytic $\mathrm{H}_{2}$-production activity of anatase $\mathrm{TiO}_{2}$ nanosheet by selectively depositing dual-cocatalysts on $\{101\}$ and $\{001\}$ facets. Appl. Catal. B Environ. 2016, 198, 286-294. [CrossRef] 
22. Ma, L.; Fan, H.; Fu, K.; Lei, S.; Hu, Q.; Huang, H.; He, G. Protonation of graphitic carbon nitride $\left(g-\mathrm{C}_{3} \mathrm{~N}_{4}\right)$ for an electrostatically self-assembling carbon@ g- $\mathrm{C}_{3} \mathrm{~N}_{4}$ core-shell nanostructure toward high hydrogen evolution. ACS Sustain. Chem. Eng. 2017, 5, 7093-7103. [CrossRef]

23. Xing, Y.; Guo, F.; Xu, M.; Gui, X.; Li, H.; Li, G.; Xia, Y.; Han, H. Separation of unburned carbon from coal fly ash: A review. Powder Technol. 2019, 353, 372-384. [CrossRef]

24. Gollakota, A.R.K.; Volli, V.; Shu, C.-M. Progressive utilisation prospects of coal fly ash: A review. Sci. Total Environ. 2019, 672, 951-989. [CrossRef]

25. Yao, Z.; Ji, X.; Sarker, P.; Tang, J.; Ge, L.; Xia, M.; Xi, Y. A comprehensive review on the applications of coal fly ash. Earth Sci. Rev. 2015, 141, 105-121. [CrossRef]

26. Karimnezhad, H.; Navarchian, A.H.; Gheinani, T.T.; Zinadini, S. Incorporation of iron oxyhydroxide nanoparticles in polyacrylonitrile nanofiltration membrane for improving water permeability and antifouling property. React. Funct. Pol. 2019, 135, 77-93. [CrossRef]

27. Visa, M.; Bogatu, C.; Duta, A. Tungsten oxide-Fly ash oxide composites in adsorption and photocatalysis. J. Hazard. Mater. 2015, 289, 244-256. [CrossRef]

28. De Valentin, C.; Pacchioni, G.; Selloni, A. Theory of carbon doping of titanium dioxide. Chem. Mater. 2005, 17, 6656-6665. [CrossRef]

29. Shi, J.-W.; Chen, S.-H.; Wang, S.-M.; Wu, P.; Xu, G.-H. Favorable recycling photocatalyst $\mathrm{TiO}_{2} / \mathrm{CFA}_{\text {: Effects }}$ of loading method on the structural property and photocatalytic activity. J. Mol. Catal. A Chem. 2009, 303, 141-147. [CrossRef]

30. Moma, J.; Baloyi, J. Modified titanium dioxide for photocatalytic applications. In Photocatalysts-Applications and Attributes; IntechOpen: London, UK, 2018; pp. 37-57. [CrossRef]

31. EL-Mekkawi, D.M.; Abdelwahad, N.A.; Mohamed, W.A.A.; Taha, N.A.; Abdel-Mottaleb, M.S.A. Solar photocatalytic treatment of industrial wastewater utilizing recycled polymeric disposals as $\mathrm{TiO}_{2}$ supports. J. Clean. Prod. 2020, 249, 119430. [CrossRef]

32. Park, J.T.; Lee, C.S.; Park, C.H.; Kim, J.H. Preparation of $\mathrm{TiO}_{2} / \mathrm{Ag}$ binary nanocomposite as high-activity visible-light-driven photocatalyst via graft polymerization. Chem. Phys. Lett. 2017, 685, 119-126. [CrossRef]

33. Behnajady, M.A.; Eskandarloo, H.; Modirshahla, N.; Shokri, M. Investigation of the effect of sol-gel synthesis variables on structural and photocatalytic properties of $\mathrm{TiO}_{2}$ nanoparticles. Desalination 2011, 278, 10-17. [CrossRef]

34. Mungondori, H.H.; Tichagwa, L.; Katwire, D.M.; Aoyi, O. Preparation of photo-catalytic copolymer grafted asymmetric membranes $\left(\mathrm{N}-\mathrm{TiO}_{2}-\mathrm{PMAA}-\mathrm{g}-\mathrm{PVDF} / \mathrm{PAN}\right)$ and their application on the degradation of bentazon in water. Iran. Pol. J. 2016, 25, 135-144. [CrossRef]

(C) 2020 by the authors. Licensee MDPI, Basel, Switzerland. This article is an open access article distributed under the terms and conditions of the Creative Commons Attribution (CC BY) license (http://creativecommons.org/licenses/by/4.0/). 